\title{
Inhibitory effects of isoscopoletin on thrombus formation via regulation of cyclic nucleotides in collagen-induced platelets
}

\author{
Dong-Ha Lee ${ }^{1,2}$ (D)
}

Received: 23 July 2020 / Accepted: 24 August 2020 / Published Online: 30 September 2020

(C) The Korean Society for Applied Biological Chemistry 2020

\begin{abstract}
An essential component of the hemostatic process during vascular damage is platelet activation. However, many cardiovascular diseases, such as atherosclerosis, thrombosis, and myocardial infarction, can develop due to excessive platelet activation. Isoscopoletin, found primarily in plant roots of the genus Artemisia or Scopolia, has been studied to demonstrate potential pharmacological effects on Alzheimer's disease and anticancer, but its mechanisms and role in relation to thrombus formation and platelet aggregation have not yet been discovered. This research investigated the effect of isoscopoletin on collagen-induced human platelet activation. As a result, isoscopoletin strongly increased cyclic adenosine monophosphate (cAMP) and cyclic guanosine monophosphate (cGMP) levels in a concentration-dependent manner. In addition, isoscopoletin greatly phosphorylated inositol 1,4,5-triphosphate receptor $\left(\mathrm{IP}_{3} \mathrm{R}\right)$ and vasodilator-stimulated phosphoprotein (VASP), known substrates of cAMP-dependent kinase and cGMP dependent kinase. Phosphorylation of $\mathrm{IP}_{3} \mathrm{R}$ by isoscopoletin induced $\mathrm{Ca}^{2+}$ inhibition from the dense tubular system $\mathrm{Ca}^{2+}$ channels, and VASP phosphorylation was involved in fibrinogen binding inhibition by inactivating $\alpha \mathrm{IIb} / \beta_{3}$ in the platelet membrane. Isoscopoletin finally reduced thrombin-induced fibrin clot production and finally reduced thrombus formation. Therefore, this research suggests that isoscopoletin has strong antiplatelet effects and is likely to be helpful for thrombotic diseases involving platelets by acting as a prophylactic and therapeutic agent.
\end{abstract}

Dong-Ha Lee $(\bowtie)$

E-mail: dhlee@nsu.ac.kr

${ }^{1}$ Department of Biomedical Laboratory Science, Namseoul University, Cheonan 31020, Republic of Korea

${ }^{2}$ Molecular Diagnostics Research Institute, Namseoul University, Cheonan 31020 , Republic of Korea

This is an Open Access article distributed under the terms of the Creative Commons Attribution Non-Commercial License (http://creativecommons. org/licenses/by-nc/3.0/) which permits unrestricted non-commercial use, distribution, and reproduction in any medium, provided the original work is properly cited.
Keywords Cyclic nucleotide · Inositol 1,4,5-triphosphate receptor - Intracellular $\mathrm{Ca}^{2+} \cdot$ Isoscopoletin · Vasodilator-stimulated phosphoprotein

\section{Introduction}

When blood vessels are damaged, the formation of a hemostatic plug depends on the essential response of platelet aggregation. However, excessive interaction between platelets and collagen relating to platelet aggregation can lead to circulatory disorders like atherosclerosis, myocardial infarction, and thrombosis [1]. Collagen supports platelet adhesion to endothelial cells and induces activation of aggregation, secretion and clotting. During collagen-induced platelet activation, an increase in the level of $\mathrm{Ca}^{2+}\left(\left[\mathrm{Ca}^{2+}\right]_{\mathrm{i}}\right)$ in the cytoplasm of platelets is an important factor causing platelet aggregation. This $\left[\mathrm{Ca}^{2+}\right]_{i}$ exists in the cell's internal storage, called a dense tubular system. It is known that calcium ions are mobilized into the cytoplasm when inositol 1,4,5triphosphate $\left(\mathrm{IP}_{3}\right)$ binds to a receptor located in the cell's internal storage [2]. The increased $\left[\mathrm{Ca}^{2+}\right]_{\mathrm{i}}$ phosphorylates the myosin light chain $(20 \mathrm{kDa})$ that relies on the $\mathrm{Ca}^{2+} /$ calmodulin complex and activates protein kinase $\mathrm{C}(\mathrm{PKC})$ in cooperation with diacy glycerol (DG). As a result, phosphorylation of pleckstrin occurs, leading to the rearrangement of cytoskeletal proteins and finally platelet aggregation [2].

In addition, DG produced by the degradation of one of the platelet membrane molecules, phosphatidylinositol 4,5-bisphosphate $\left(\mathrm{PIP}_{2}\right)$, is continuously hydrolyzed by DG lipase and mono acylglycerol lipase to produce arachidonic acid and converted to thromboxane $\mathrm{A}_{2}\left(\mathrm{TXA}_{2}\right)$ [3]. $\mathrm{TXA}_{2}$ is known to induce platelet secretion and morphological changes by activating platelets [4]. As a matter of fact, the TXA 2 analogue, U46619 (9,11-dideoxy9a.1la-methanoepoxy prostaglandin F2a), has proved to be an effective platelet aggregation inducer that increases $\left[\mathrm{Ca}^{2+}\right]_{\mathrm{i}}$ resulting in the phosphorylation of pleckstrin and myosin light chain $[5,6]$. 
This is the normal process of haemostatic reaction of blood, but if excessive platelet aggregation occurs, various vascular diseases, such as atherosclerosis, can develop. Therefore, appropriate inhibition of platelet activation may be a useful approach to the prevention of cardiovascular disease [5,6].

Antiplatelet agents, verapamil and theophylline, are known to function by increasing the level of circulating adenosine monophosphate (cAMP), which reduces $\left[\mathrm{Ca}^{2+}\right]_{\mathrm{i}}$, an essential component of platelet aggregation [7]. In addition, platelet cyclic guanosine monophosphate (cGMP) levels are increased using cGMP phosphodiesterase (PDE) inhibitors such as zaprinast and erythro9-(2-hydroxy-3-nonyl) adenine, and vasodilators such as nitroprusside and molsidomine [8]. During normal blood circulation, vascular endothelial cells let out prostaglandin $\mathrm{I}_{2}$ and nitric oxide leading to cAMP and cGMP production from platelets. Increased cAMP level induces activation of protein kinase A (PKA), while an increase in cGMP level induces activation of protein kinase $G$ (PKG). PKA and PKG are known to cause phosphorylation of the substrate proteins vasodilator-stimulated phosphoprotein (VASP) and inositol 1,4,5-triphosphate receptor $\left(\mathrm{IP}_{3} \mathrm{R}\right)$ [9]. Phosphorylation of $\mathrm{IP}_{3} \mathrm{R}$ inactivates the receptor, inhibiting dense tubular system $\mathrm{Ca}^{2+}$ mobilization into the cytoplasm $[7,10]$. In platelets, VASP is the main substrate of PKA and PKG, and assists in modulating the activation of $\alpha \mathrm{IIb} / \beta_{3}$ and actin filament activity. Phosphorylation of cGMP-dependent VASP $\operatorname{Ser}^{239}$ or phosphorylation of cAMPdependent VASP Ser ${ }^{157}$ can lead to inhibition of $\alpha \mathrm{IIb} / \beta_{3}$ activation as well as actin filament elongation inhibition $[11,12]$. Consequently, the phosphorylation of $\mathrm{IP}_{3} \mathrm{R}$ is essential to confirm the antiplatelet effect since it inhibits $\mathrm{Ca}^{2+}$ mobilization and the phosphorylation of VASP is essential to confirm the antiplatelet effect since it inhibits the activity of platelets through $\alpha \mathrm{IIb} / \beta_{3}$ inhibition.

Isoscopoletin, found primarily in plant roots of the genus Artemisia or Scopolia, has been studied for medicinal properties that may prove beneficial for Alzheimer's disease and anti-cancer $[13,14]$. However, the role and mechanism of 6-hydroxy-7-methoxy$2 \mathrm{H}$-chromen-2-one (Isocopoletin) in human platelet activation is unknown. To elucidate the antiplatelet effect of isoscopoletin, we examined the actions of isoscopoletin on calcium mobilization through the regulation of cyclic nucleotides, and thrombus formation through fibrinogen binding. We also investigated whether isoscopoletin is involved ultimately in platelet activation and thrombus formation. If isoscopoletin is shown to be an effective antiplatelet agent, it is expected that isoscopoletin will contribute to the CVD prevention caused by thrombosis.

\section{Materials and Methods}

\section{Materials}

Isocopoletin was provided from Avention Corporation (Seoul, Korea) (Fig. 1). Isocopoletin was dissolved in dimethyl sulfoxide (DMSO) solution to $0.25 \%$ finally, and the same concentration of<smiles>COc1cc2oc(=O)ccc2cc1O</smiles>

Fig. 1 The structure of isoscopoletin. PIN: 6-hydroxy-7-methoxy-2Hchromen-2-one, Chemical formula: $\mathrm{C}_{10} \mathrm{H}_{8} \mathrm{O}_{4}$, Molar mass: $192.17 \mathrm{~g} / \mathrm{moL}$

DMSO was added to the control not pretreated with isocopoletin. The Enzyme Immunoassay (EIA) kits for cAMP and cGMP were provided by Cayman Chemical (Ann Arbor, MI, USA). Collagen was bought from Chrono-Log Corporation (Havertown, PA, USA). Fura 2-AM was bought from Invitrogen (Eugene, OR, USA). Anti-phospho-IP ${ }_{3} \mathrm{R}$ type I, Anti-VASP, Anti-phospho-VASP Ser157, Anti-phospho-VASP Ser239, anti- $\beta$-actin, anti-rabbit IgGHRP-conjugate, and lysis buffer were provided by Cell Signaling (Beverly, MD, USA). Polyvinylidene difluoride (PVDF) membranes was provided by Thermos fisher scientific Corporation (Middlesex County, MA, USA). Invitrogen Molecular Probes supplied Enhanced chemiluminescence solution (ECL) and Fibrinogen Alexa Fluor 488 conjugate.

\section{Preparation of human washed platelets}

Korean Red Cross Blood Source (Suwon, Korea) supplied Human platelet-rich plasma (PRP). The human washed platelets were prepared according to the previously performed method [15]. To obtain the concentrate platelets, PRP was centrifuged for 10 minutes at $1,300 \times \mathrm{g}$ and washed with buffer $\left(12 \mathrm{mM} \mathrm{NaHCO}_{3}\right.$, $2.7 \mathrm{mM} \mathrm{KCl}, 0.36 \mathrm{mM} \mathrm{NaH}_{2} \mathrm{PO}_{4}, 138 \mathrm{mM} \mathrm{NaCl}, 1 \mathrm{mM} \mathrm{Na} 2$ EDTA, 5. $\mathrm{mM}$ glucose, and $\mathrm{pH}$ 6.9). Washed twice, the platelets suspended with suspension buffer $(12 \mathrm{mM} \mathrm{NaHCO} 3,2.7 \mathrm{mM}$ $\mathrm{KCl}, 0.36 \mathrm{mM} \mathrm{NaH}{ }_{2} \mathrm{PO}_{4}, 138 \mathrm{mM} \mathrm{NaCl}, 5.5 \mathrm{mM}$ glucose, $0.49 \mathrm{mM}$ $\mathrm{MgCl}_{2}, 0.25 \%$ gelatin, and $\mathrm{pH} 7.4$ ) to a final concentration of $10^{8}$ cells $/ \mathrm{mL}$. The above procedure was performed at room temperature to experiment while avoiding platelet aggregation at low temperature, and approval was obtained from the Institutional Review Board (IRB) of the University of Namseoul to perform this experiment (1041479-HR-201803-003).

\section{Measurement of cyclic nucleotides (cAMP and cGMP) production}

Washed platelets $\left(10^{8}\right.$ cells $\left./ \mathrm{mL}\right)$ incubation occurred for 3 minutes at $37^{\circ} \mathrm{C}, 2 \mathrm{mM} \mathrm{CaCl}_{2}$ was added, followed with stimulation by collagen $(2.5 \mu \mathrm{g} / \mathrm{mL})$ to induce aggregation for 5 minutes. Reaction termination happened with the addition of $1 \mathrm{M} \mathrm{HCl}$, and cAMP or cGMP was measured using an EIA kit through a Synergy HT Multi-Model Microplate Reader (BioTek Instruments, Winooski, Vermont, USA).

\section{Measurement of intracellular $\mathrm{Ca}^{2+}$ mobilization}

$5 \mu \mathrm{M}$ of Fura 2-AM was incubated with the PRP at $37{ }^{\circ} \mathrm{C}$ for 60 minutes, prepared from washed platelets $\left(10^{8}\right.$ cells $\left./ \mathrm{mL}\right)$ following 
the process mentioned above, and $2 \mathrm{mM} \mathrm{CaCl} 2$ was added to incubate at $37{ }^{\circ} \mathrm{C}$ for $3 \mathrm{~min}$, stimulated with collagen $(2.5 \mu \mathrm{g} / \mathrm{mL})$, and measured for $5 \mathrm{~min}$. Measuring of Fura 2 fluorescence was done with a spectral fluorescence photometer (SFM 25, Winooski, VT, USA) of BioTec Instrument (SFM 25). A $340 \mathrm{~nm}$ initial excitation wavelength was set. With the ultimate excitation wavelength reaching $510 \mathrm{~nm}$, increasing in increments of 0.5 seconds. The emission wavelength used a $510 \mathrm{~nm}$ setting. The amount of $\mathrm{Ca}^{2+}$ mobilization was calculated with Grynkiewicz's method [16].

\section{Immunoblotting}

The reaction was terminated by adding $1 \mathrm{x}$ lysis buffer. The protein concentration of platelet lysates were measured using a BCA protein kit (Pierce Biotechnology, IL, USA). Protein $(20 \mu \mathrm{g})$ was separated via 4-20\% SDS-PAGE and transferred to PVDF membrane. A dilution factor of 1:1,000 was used to treat the primary antibody, and a dilution factor of 1:2,000 was used to treat the secondary antibody. Visualization was done using ECL reagent (Invitrogen Molecular Probes).

\section{Fibrinogen binding measurement}

After treatment of washed platelets $\left(10^{8}\right.$ cells $\left./ \mathrm{mL}\right)$ with $2 \mathrm{mM}$ $\mathrm{CaCl}_{2}$ and Fibrinogen Alexa Fluor 488 conjugate $(30 \mu \mathrm{g} / \mathrm{mL})$, stimulation with collagen $(2.5 \mu \mathrm{g} / \mathrm{mL})$ was measured for 5 minutes. The reaction termination was carried out with the addition of phosphate-buffered saline (PBS, pH 7.4) with $0.5 \%$ paraformaldehyde. The above process was performed in state of blocking light, and the binding of fibrinogen was measured with FACS and analyzed with Cell-Quest software (BD Bioscience, San Jose, CA, USA).

\section{Platelet mediated fibrin clot formation measurement}

Transfering of PRP $(500 \mu \mathrm{L})$ to a polyethylene tube was done to prevent adhesion and stimulated for $15 \mathrm{~min}$ at $37^{\circ} \mathrm{C}$ with thrombin $(0.05 \mathrm{U} / \mathrm{mL})$ and the addition of $2 \mathrm{mM} \mathrm{CaCl}_{2}$. Pictures of the fibrin clot were collected with a digital camera. Calculation of the coagulation area was completed using ImageJ Software (v1.46, National Institutes of Health, Bethesda, MD, USA).

\section{Statistical analyses}

Experimental results are presented as mean \pm standard deviation. The Student's t-test or ANOVA was used for statistical analysis, and if $p<0.05$, the value was considered statistically significant. If there was a significant difference between the group means according to the ANOVA, the each group was compared using Scheffe's method.

\section{Results}

Effects of isoscopoletin on the production of cyclic nucleotides The effect of isoscopoletin on cAMP or cGMP production was confirmed. As shown in Fig. 2A, isoscopolein heightened cAMP
(A)

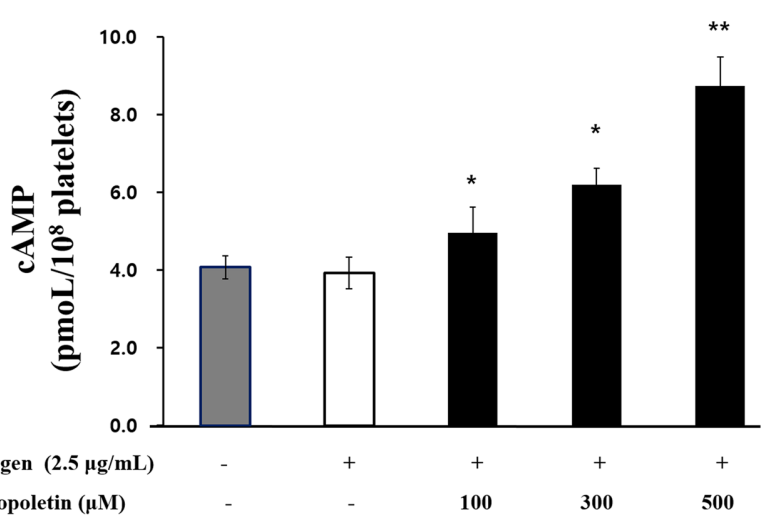

(B)

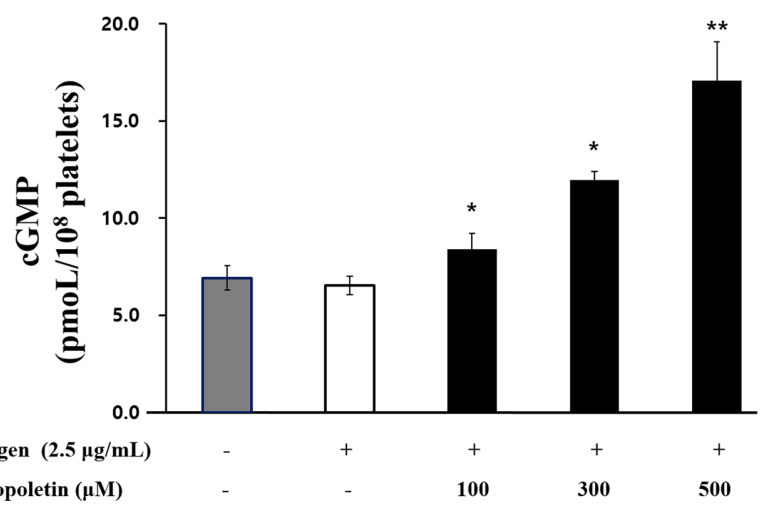

Fig. 2 Effects of isoscopoletin on cyclic nucleotides production. (A) Effects of isoscopoletin on cAMP production stimulated by collagen. (B) Effects of isoscopoletin on cGMP production stimulated by collagen. Data are expressed as means $\pm \mathrm{SD}(\mathrm{n}=4) .{ }^{*} p<0.05$, $* * p<0.001$ compared with the collagen-stimulated platelets

production from $3.92 \pm 0.41 \mathrm{pmoL} / 10^{8}$ platelets to $8.74 \pm 0.74$ $\mathrm{pmoL} / 10^{8}$ platelets, and cGMP production from $6.53 \pm 0.46 \mathrm{pmoL} /$ $10^{8}$ platelets to $17.09 \pm 1.98 \mathrm{pmoL} / 10^{8}$ platelets significantly (Fig. 2B). In particular, with a $100 \mu \mathrm{M}$ isoscopolein concentration or higher, the significance was clearly observed, and a stronger increase in cGMP than cAMP was observed. These results show that in collagen-induced platelets, isoscopolein inhibits the platelet activation, significantly increasing the production of cAMP and cGMP.

Effects of isoscopoletin on intracellular $\mathrm{Ca}^{2+}$ mobilization and $\mathrm{IP}_{\mathbf{3}} \mathbf{R}$ phosphorylation

Knowing that intracellular $\mathrm{Ca}^{2+}$ mobilization $\left(\left[\mathrm{Ca}^{2+}\right]_{\mathrm{i}}\right)$ is crucial for the platelet activation, this study verified the effects of isoscopolein on $\left[\mathrm{Ca}^{2+}\right]_{\mathrm{i}}$. The level of $\left[\mathrm{Ca}^{2+}\right]_{\mathrm{i}}$ was increased from $101.2 \pm 0.8$ to $632.1 \pm 16.8 \mathrm{nM}$ by collagen (Fig. $3 \mathrm{~A}$ ). However, isoscopolein $(100 \sim 500 \mu \mathrm{M})$ significantly decreased the concentration of $\left[\mathrm{Ca}^{2+}\right]_{i}$ increased by collagen in a concentration-dependently. The inhibition rate of $\left[\mathrm{Ca}^{2+}\right]_{\mathrm{i}}$ of isoscopoletin $(500 \mu \mathrm{M})$ was up to $82.3 \%$. Furthermore, this study verified the effect isoscopolein had on phosphorylation of $\left[\mathrm{Ca}^{2+}\right]_{i}$-regulating protein $\mathrm{IP}_{3} \mathrm{R}$. As 


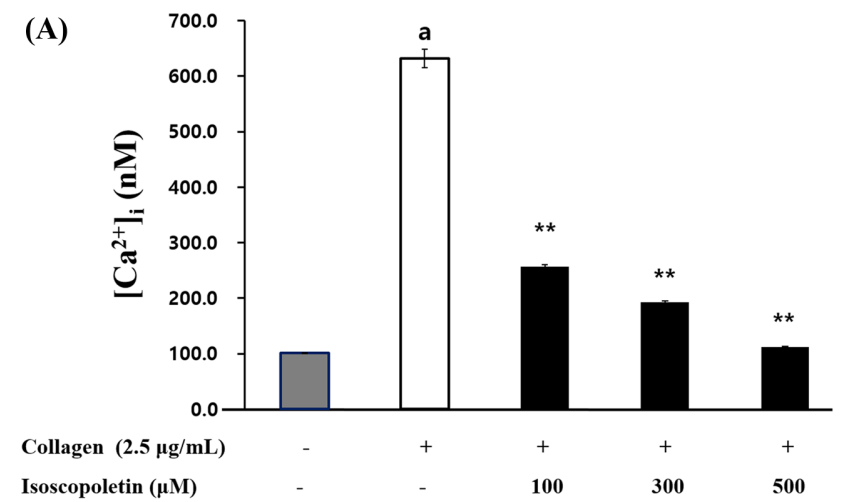

(B)

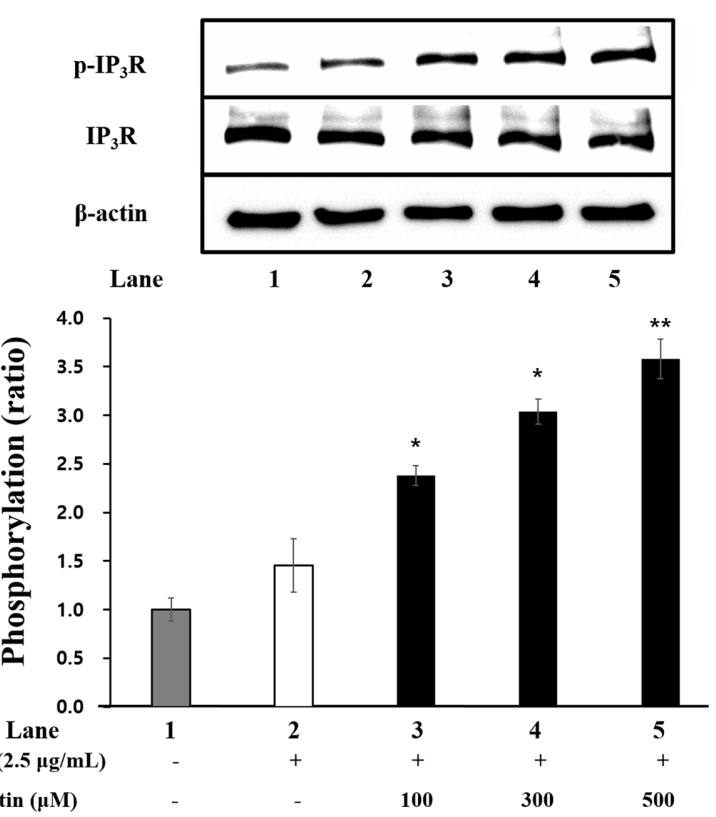

Fig. 3 Effects of isoscopoletin on $\left[\mathrm{Ca}^{2+}\right]_{i}$ mobilization and $\mathrm{IP}_{3} \mathrm{R}$ phosphorylation. (A) Inhibitory effects of isoscopoletin on collageninduced $\left[\mathrm{Ca}^{2+}\right]_{\mathrm{i}}$ mobilization. (B) Effects of isoscopoletin on collageninduced $\mathrm{IP}_{3} \mathrm{R}$ phosphorylation. Measurement of $\left[\mathrm{Ca}^{2+}\right]_{i}$ mobilization and Western blotting was described in "Materials and Methods" section. The data are expressed as the mean \pm standard deviation $(\mathrm{n}=4) .{ }^{\mathrm{a}} p<0.05$ compared with no-stimulated platelets, ${ }^{*} p<0.05,{ }^{* *} p<0.001$ compared with the collagen-stimulated platelets

shown in Fig. 3B, isoscopolein (100-500 $\mu \mathrm{M})$ increased, concentrationdependently, $\mathrm{IP}_{3} \mathrm{R}$ phosphorylation in collagen-induced platelets, and it was confirmed that there were significant results at concentrations above $100 \mu \mathrm{M}$. These results indicate that the decrease in intracellular $\mathrm{Ca}^{2+}$ mobilization by isoscopolein is due to $\mathrm{IP}_{3} \mathrm{R}$ phosphorylation.

\section{Effects of isoscopoletin on VASP Phosphorylation}

Because isoscopoletin increased production of both cAMP and cGMP in collagen-induced platelets in a concentration-dependently (Fig. 2), isoscopoletin in this study might affect the phosphorylation of both cAMP and cGMP dependent VASP $\operatorname{Ser}^{157}$ and $\mathrm{Ser}^{239}$ in

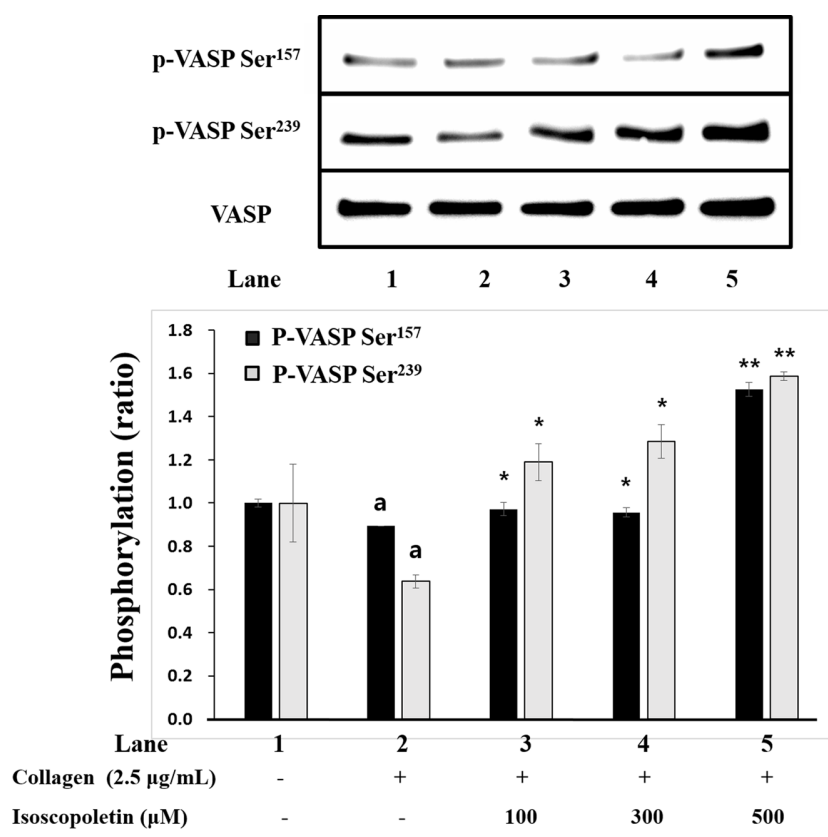

Fig. 4 Effects of isoscopoletin on VASP phosphorylation. Western blotting was determined as described in "Materials and Methods" section. The data are expressed as the mean \pm standard deviation $(\mathrm{n}=4) .{ }^{\mathrm{a}} p<0.05$ compared with no-stimulated platelets, ${ }^{*} p<0.05,{ }^{* *} p<0.001$ compared with the collagen-stimulated platelets

collagen-induced platelets. As shown in Fig. 4, VASP $\operatorname{Ser}^{157}$ and VASP $\operatorname{Ser}^{239}$ phosphorylation were increased significantly with increasing concentration of isoscopoletin. Specifically, it was established that the significance was clearly observed at a concentration of $100 \mu \mathrm{M}$ or more, and the extent of phosphorylation of VASP $\operatorname{Ser}^{239}$ was stronger than that of VASP Ser ${ }^{157}$. This result is consistent with the trend of heightened cAMP and cGMP production by isoscopoletin, showing that the increase in cAMP and cGMP production led to phosphorylation of VASP.

\section{Effects of isoscopoletin on fibrinogen binding to $\alpha \mathbf{I I b} / \beta_{3}$}

Because isoscopoletin heightened phosphorylation of VASP Ser ${ }^{157}$ and VASP Ser $^{239}$ by means of increased cAMP and cGMP, the effects of isoscopoletin on the fibrinogen binding capacity to $\alpha \mathrm{IIb} /$ $\beta_{3}$ was confirmed in this study. Collagen increased fibrinogen binding to $\alpha \mathrm{IIb} / \beta_{3}$ at a rate of $84.8 \pm 1.1 \%$ (Fig. $5 \mathrm{~A}-\mathrm{b}, 5 \mathrm{~B}$ ) than intact cell $(0.6 \pm 0.2 \%)$. However, it was confirmed that the fibrinogen binding was inhibited by isoscopoletin in a concentrationdependently, and in particular, the significance was clearly shown at a concentration of $100 \mu \mathrm{M}$ or higher. In addition, the inhibition rate of isoscopoletin $(500 \mu \mathrm{M})$ was confirmed to be $80.2 \%$ (Fig. $5 \mathrm{~A}-\mathrm{c} \sim \mathrm{e}, 5 \mathrm{~B})$.

Effects of isoscopoletin on platelet-mediated fibrin clot formation Over time, as the binding of fibrinogen is increased by activation of $\alpha \mathrm{IIb} / \beta_{3}$ through a platelet activator, fibrin clot is formed through an external $\alpha \mathrm{IIb} / \beta_{3}$ signal transduction pathway. Therefore, 
(A)
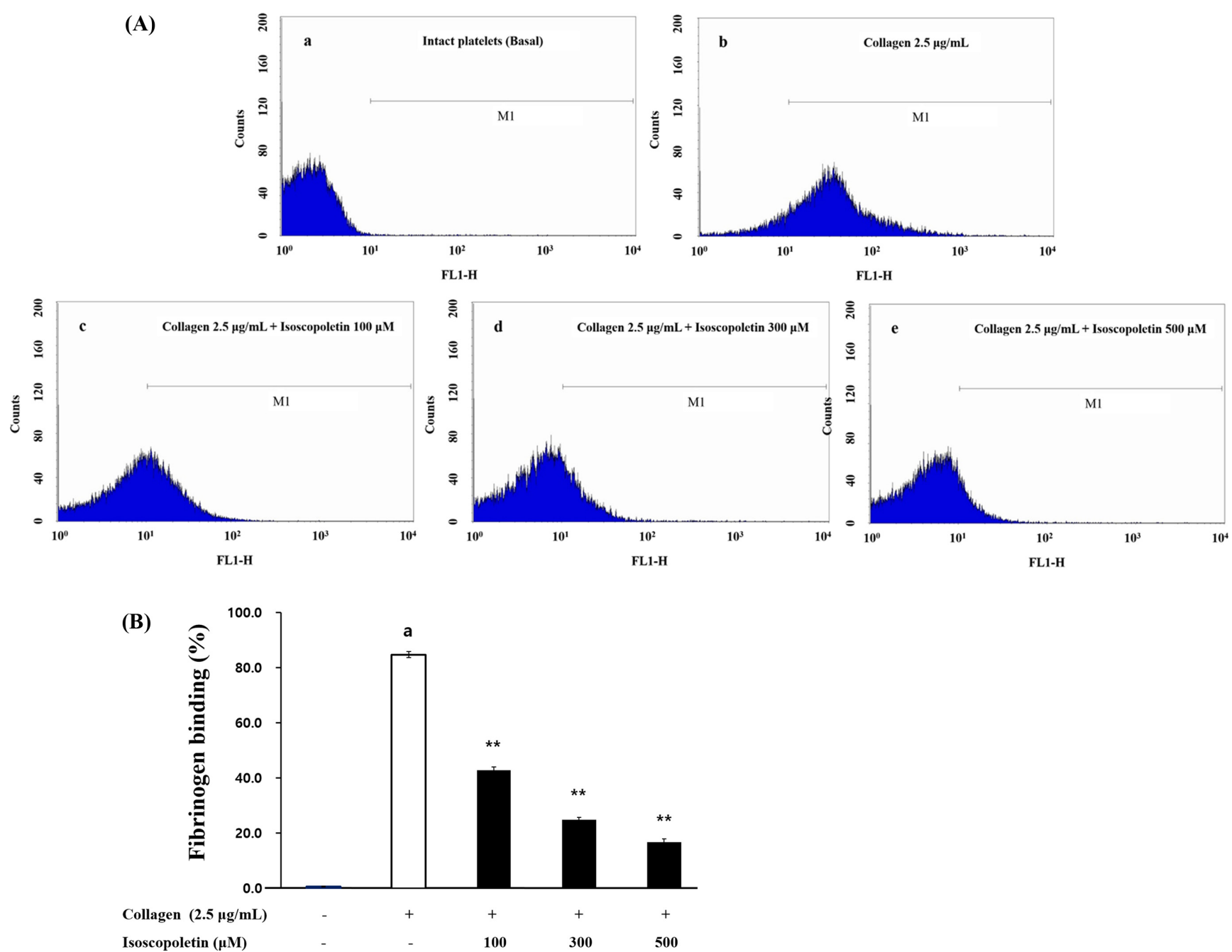

Fig. 5 Effects of isoscopoletin on collagen-induced fibrinogen binding. (A) The flow cytometry histograms on fibrinogen binding. a, Intact platelets (base); b, collagen $(2.5 \mu \mathrm{g} / \mathrm{mL})$; c, collagen $(2.5 \mu \mathrm{g} / \mathrm{mL})+$ isoscopoletin $(100 \mu \mathrm{M})$; d, collagen $(2.5 \mu \mathrm{g} / \mathrm{mL})+$ isoscopoletin $(300 \mu \mathrm{M}))$; e, collagen $(2.5 \mu \mathrm{g} / \mathrm{mL})+$ isoscopoletin $(500 \mu \mathrm{M})$. (B) Effects of isoscopoletin on collagen-induced fibrinogen binding (\%). Measurement of fibrinogen binding was described in "Materials and Methods" section. The data are expressed as the mean \pm standard deviation $(\mathrm{n}=4)$. ${ }^{\mathrm{a}} p<0.05$ compared with nostimulated platelets, ${ }^{*} p<0.05,{ }^{* *} p<0.001$ compared with the collagen-stimulated platelets

this study measured the effects of isoscopoletin on thrombinactivated fibrin clot formation. As shown in Fig. 6A, fibrin clot was greatly formed by thrombin, and isoscopoletin $(100,300$ and $500 \mu \mathrm{M})$ inhibited thrombin-induced formation of fibrin clot in a concentration-dependent manner, especially in concentrations above $100 \mu \mathrm{M}$. The inhibition rates of isoscopoletin (100, 300 and $500 \mu \mathrm{M})$ were confirmed to be $22.2,57.4$, and $77.5 \%$, respectively (Fig. 6B).

\section{Discussion}

When platelet activation occurs, the activated phospholipase $\mathrm{C}-\gamma_{2}$ (PLC- $\left.\gamma_{2}\right)$ hydrolyze Phosphatidylinositol 4,5-bisphosphate ( $\left.\mathrm{PIP}_{2}\right)$ on the platelet membrane. This results in diacylglycerol (DG) as well as inositol 1,4,5-triphosphate $\left(\mathrm{IP}_{3}\right)$. The produced $\mathrm{IP}_{3}$ let go $\mathrm{Ca}^{2+}$ mobilization into cells from dense tubular system $\left(\left[\mathrm{Ca}^{2+}\right]_{\mathrm{i}}\right)$ and relies on DG-dependent PKC for activation [17]. Platelet activation results from phosphorylated $\mathrm{Ca}^{2+} /$ calmodulin-dependent proteins, pleckstrin (40 or $47 \mathrm{kDa}$ ) and myosin light chain (20 $\mathrm{kDa})$, which is caused by the increased $\left[\mathrm{Ca}^{2+}\right]_{\mathrm{i}}[18]$.

On the other hand, cyclic nucleotides (cAMP and cGMP) are known to suppress platelet aggregation through a reduction in $\left[\mathrm{Ca}^{2+}\right]_{\mathrm{i}}$, and cause activation of cAMP-dependent protein kinase (PKA) in addition to cGMP-dependent protein kinase (PKG) [19]. In this study, isoscopoletin significantly heightened cAMP and cGMP production and inhibited $\left[\mathrm{Ca}^{2+}\right]_{\mathrm{i}}$ in platelets concentrationdependently. These results indicate that cyclic nucleotides, with increased production by isoscopoletin, play a central role in the inhibition of platelet activity through the reduction of $\left[\mathrm{Ca}^{2+}\right]_{i}$. The 
(A)
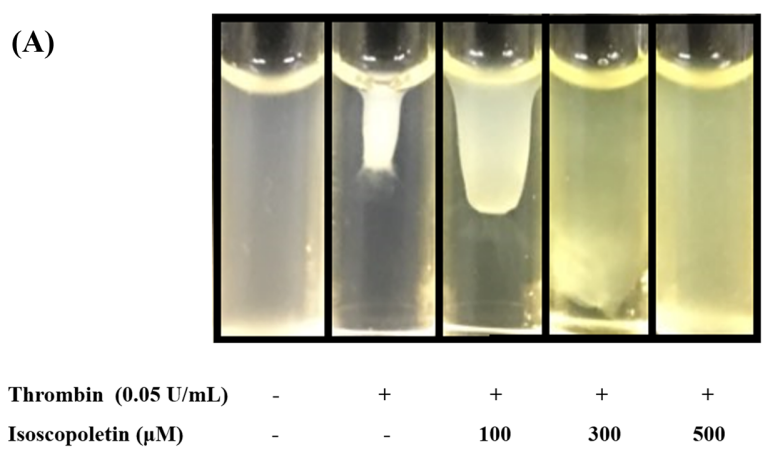

(B)

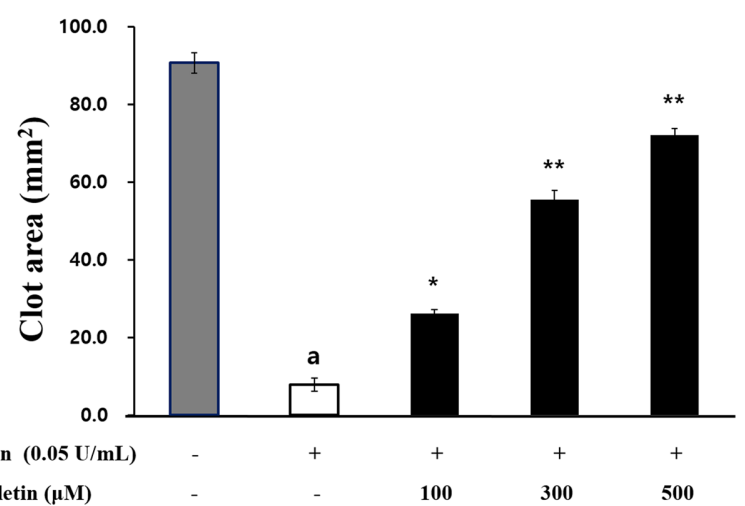

Isoscopoletin $(\mu \mathrm{M})$

100

00

Fig. 6 Effects of isoscopoletin on fibrin clot retraction. (A) Effects of isoscopoletin on thrombin-retracted fibrin clot photographs (B) Effects of isoscopoletin on thrombin-retracted fibrin clot area. Quantification of fibrin clot retraction was described in "Materials and Methods" section. The data are expressed as the mean \pm standard deviation $(n=4) .{ }^{a} p<0.05$ compared with no-stimulated platelets, ${ }^{*} p<0.05,{ }^{* *} p<0.001$ compared with the thrombin-stimulated platelets

heightened cAMP and cGMP are used to phosphorylate several substrate proteins by activating PKA and PKG, and are known to make an effect on $\mathrm{IP}_{3}$ receptor $\left(\mathrm{IP}_{3} \mathrm{R}\right)$ through phosphorylation of substrates [9].

As shown in Fig. 3A, isoscopoletin strongly phosphorylates $\mathrm{IP}_{3} \mathrm{R}$ in a concentration-dependently. The result demonstrates that the activation of PKA and PKG resulting from isoscopoletin led to the phosphorylation of $\mathrm{IP}_{3} \mathrm{R}$, thus preventing the $\mathrm{Ca}^{2+}$ channel in dense tubular system from opening and reducing $\left[\mathrm{Ca}^{2+}\right]_{\mathrm{i}}$. In addition, the increased cAMP and cGMP due to isoscopoletin led to phosphorylation of their substrate, VASP, via the activation of PKA and PKG. It is known that VASP functions as a vital substrate of cAMP/cGMP-dependent PKA/PKG which regulates the activation of platelets through the control of platelet adhesion and secretion properties, and the phosphorylated VASP inhibits integrin $\alpha \mathrm{IIb} / \beta_{3}$ activation causing the inhibition of platelet aggregation $[20,21]$.

In this research, isoscopoletin significantly inhibited fibrinogen binding to $\alpha \mathrm{Il} b / \beta_{3}$ on collagen-induced platelets. The phosphorylation of PKA-dependent VASP Ser ${ }^{157}$ and PKG-dependent VASP Ser ${ }^{239}$ by activation of PKA and PKG is thought to be due to isoscopoletin, which could raise the levels of cAMP and cGMP. Furthermore, integrin $\alpha \mathrm{Ilb} / \beta_{3}$-mediated signal transduction generally causes platelet cytoskeleton deformation, which makes effects on platelet proliferation and thrombus production. Thrombus production is the most important point during the repair on damaged parts of blood vessels, and activated platelets are accumulated in damaged blood vessels resulting in fibrin platelet meshwork development. The formation of fibrin clot acting on hemostasis of damaged blood vessels initiates contraction for a duration of 30 to 60 minutes and results in the creation of a thrombus by pulling the created plug. An important role in fibrin clot formation is the interaction between $\alpha \mathrm{IIb} / \beta_{3}$ and fibrinogen, and $\alpha \mathrm{IIb} / \beta_{3}$ activity inhibitors have been shown to greatly inhibit thrombus formation [22]. Thrombin activates platelets integrin to increase the binding capacity of fibrinogen to $\alpha \mathrm{IIb} / \beta_{3}$, resulting in clot production. As shown in Fig. 6, the antiplatelet effects of isoscopoletin caused the suppression of thrombin-activated fibrin clot, which is the underlying reason for thrombosis inhibition, in a concentrationdependently. This result shows that isoscopoletin is likely to be a potent antiplatelet agent that heighten cAMP and cGMP production, and thus inhibit thrombus production.

In next studies, research is needed on the mechanism by which isoscopoletin heightened cAMP and cGMP production. According to a previous study, scoparone, a substance with a structure similar to isoscopoletin, has been reported to promote penile erection through vasodilation due to an increase in nitric oxide (NO) and an increase in cGMP production [23]. NO is known to increase the production of cGMP by activating NO sensitive guanylyl cyclase (NO-GC) in platelets. This effect could cause cGMP production with the increase of activated NO-GC, promoting thrombolysis [24]. In line with the results of this experiment, it was confirmed that isoscopoletin significantly increased cGMP production, possibly resulting from an increase in NO by isoscopoletin. In addition, cyclic nucleotides phosphodiesterase (PDE) or adenylyl cyclase/guanyl cyclase activation is a factor for cAMP and cGMP levels [25]. Since the PDE activity inhibition increases cyclic nucleotides levels during platelet aggregation, therapeutic effects on thrombosis have been reported with the use of PDE inhibitors [26]. As expected, triple rusal, cilostazol, and dipyridamole, all of which act as PDE inhibitors, have been used as the antiplatelet agents that clinically increase the level ofcyclic nucleotides [8]. Isoscopoletin is likely to be developed as a drug that acts as an antiplatelet through a similar mechanism.

In conclusion, isoscopoletin induces $\mathrm{IP}_{3} \mathrm{R}$ and VASP phosphorylation in human platelets by heightening cAMP and cGMP, significantly inhibiting both the mobilization of $\mathrm{Ca}^{2+}$ into the cytoplasm and activation of integrin $\alpha \mathrm{IIb} / \beta_{3}$, and finally, thrombininduced fibrin clot production was inhibited concentrationdependently. Therefore, this research suggests that isoscopoletin can be effectively developed as antithrombotic and therapeutic agents. 
Acknowledgments Namseoul University provided funding for this paper.

Conflict of interest The authors of this paper have declared no conflicts of interest.

\section{References}

1. Schwartz SM, Heimark RL, Majesky MW (1990) Developmental mechanisms underlying pathology of arteries. Physiol Rev 70: 1177 1209

2. Furuichi T, Mikoshiba K (1995) Inositol 1, 4, 5-trisphosphate receptormediated $\mathrm{Ca}^{2+}$ signaling in the brain. J Neurochem 64: 953-960

3. Ohkubo S, Nakahata N, Ohizumi Y (1996) Thromboxane A2-mediated shape change: independent of Gq-phospholipase $\mathrm{C}_{-} \mathrm{Ca}^{2+}$ pathway in rabbit platelets. Br J Pharmacol 117: 1095-1104

4. Saitoh M, Naka M, Hidaka H (1986) The modulatory role of myosin light chain phosphorylation in human platelet activation. Biochem Biophys Res Commun 140: 280-287

5. Cattanco M, Tenconi PM, Lecchi A, Mannucci PM (1991) In vitro effects of picotamide on human platelet aggregation, the release reaction and thromboxane B2 production. Thromb Res 62: 717-724

6. Su CY, Shiao MS, Wang CT (1999) Differential effects of ganodermic acid $\mathrm{S}$ on the thromboxane A2-signaling pathways in human platelets. Biochem Pharmacol 58: 587-595

7. Quinton TM, Dean WL (1992) Cyclic AMP-dependent phosphorylation of the inositol-1,4,5-trisphosphate receptor inhibits $\mathrm{Ca}^{2+}$ release from platelet membranes. Biochemical and Biochem Biophys Res Commun 184: 893-899

8. Menshikov MYU, Ivanova K, Schaefer M, Drummer C, Gerzer R (1993) Influence of the cGMP analog 8-PCPT-cGMP on agonist-induced increases in cytosolic ionized $\mathrm{Ca}^{2+}$ and on aggregation of human platelets. Eur J Pharmacol 245: 281-284

9. Schwarz UR, Walter U, Eigenthaler M (2001) Taming platelets with cyclic nucleotides. Biochem Pharmacol 62: 1153-1161

10. Cavallini L, Coassin M, Borean A, Alexandre A (1996) Prostacyclin and sodium nitroprusside inhibit the activity of the platelet inositol 1,4,5trisphosphate receptor and promote its phosphorylation. J Biol Chem 271: 5545-5551

11. Laurent V, Loisel TP, Harbeck B, Wehman A, Gröbe L, Jockusch BM, Frank JW, Gertler,B, Carlier MF (1999) Role of proteins of the Ena/ VASP family in actin-based motility of Listeria monocytogenes. J Cell Biol 144: 1245-1258

12. Sudo T, Ito H, Kimura Y (2003) Phosphorylation of the vasodilatorstimulated phosphoprotein (VASP) by the anti-platelet drug, cilostazol, in platelets. Platelets 14: 381-390
13. Ali MY, Jannat S, Jung HA, Choi RJ, Roy A, Choi JS (2016) AntiAlzheimer's disease potential of coumarins from Angelica decursiva and Artemisia capillaris and structure-activity analysis. Asian Pac J Trop Med 9(2): 103-111

14. Dong J, Yuan J, Wang JL, Ji RF, Quan QH, Guo XY, Gao J, Liu YG (2017) Study on screening antitumor active fractions and chemical components in active fractions from root of Anaycclus pyrethrum. Zhongguo Zhong Yao Za Zhi 42(20): 3932-3937

15. Shin JH, Kwon HW, Lee DH (2019) Ginsenoside F4 inhibits platelet aggregation and thrombus formation by dephosphorylation of IP3RI and VASP. J Appl Biol Chem 62: 93100

16. Grynkiewicz G, Poenie M, Tsien RY (1985) A new generation of $\mathrm{Ca}^{2+}$ indicators with greatly improved fluorescence properties. J Biol Chem 260: $3440-3450$

17. Berridge MJ, Irvine RF (1989) Inositol phosphates and cell signalling. Nature 341: 197-205

18. Nishikawa M, Tanaka T, Hidaka H (1980) $\mathrm{Ca}^{2+}$-calmodulin-dependent phosphorylation and platelet secretion. Nature 287: 863-865

19. Kuo JF, Andersson RG, Wise BC, Mackerlova L, Salomonsson I, Brackett NL, Katoh N, Shoji M, Wrenn RW (1980) Calcium $\neg$ dependent protein kinase: widespread occurrence in various tissues and phyla of the animal kingdom and comparison of effects of phospholipid, calmodulin, and trifluoperazine. Proc Natl Acad Sci 77: 7039-7043

20. Wangorsch G, Butt E, Mark R, Hubertus K, Geiger J, Dandekar T, Dittrich M (2011) Time-resolved in silico modeling of finetuned cAMP signaling in platelets: feedback loops, titrated phospho-rylations and pharmacological modulation, BMC Syst Biol 5: 178

21. Napeñas J, Oost FC, DeGroot A, Loven B, Hong CH, Brennan MT, Lockhart PB, van Diermen DE (2013) Review of postoperative bleeding risk in dental patients on antiplatelet therapy. Oral Surg Oral Med Oral Pathol Oral Radiol 115: 491-499

22. Topol EJ, Byzova TV, Plow EF (1999) Platelet GPIIb-IIIa blockers. The Lancet 353: 227-231

23. Choi BR, Kim HK, Park JK (2017) Penile erection induced by scoparone from Artemisia capillaris through the nitric oxide-cyclic guanosine monophosphate signaling pathway. World J Mens Health 35: 196-204

24. Wen L, Feil S, Wolters M, Thunemann M, Regler F, Schmidt K, et al., Andreas Friebe A, Olbrich M, Langer H, Gawaz M, de Wit C, Feil R (2018) A shear-dependent NO-cGMP-cGKI cascade in platelets acts as an auto-regulatory brake of thrombosis. Nat Commun. 16: 4301

25. Gao J, Tao J, Liang W, Zhao M, Du X, Cui S, Duan H, Kan B, Su X, Jiang Z (2015) Identification and characterization of phosphodiesterases that specifically degrade 3'3'-cyclic GMP-AMP. Cell Res 25: 539-550

26. Haslam RJ, Dickinson NT, Jang EK (1999) Cyclic nucleotides and phosphodiesterases in platelets. Thromb Haemost 82: 412-423 